Research Article

\title{
Experimental Study on Deformation Monitoring of Large Landslide in Reservoir Area of Hydropower Station Based on GB-InSAR
}

\author{
Yanhui Guo $\left(\mathbb{D},{ }^{1,2}\right.$ Zhiquan Yang $\mathbb{D}^{1},{ }^{1}$ Yi Yang $\left(\mathbb{D},{ }^{1}\right.$ Zhijun Kong, ${ }^{1}$ Caikun Gao, ${ }^{2}$ \\ and Weiming Tian ${ }^{3}$ \\ ${ }^{1}$ Faculty of Public Safety and Emergency Management, Kunming University of Science and Technology, Kunming 650093, China \\ ${ }^{2}$ PowerChina Kunming Engineering Corporation Limited, Kunming 650051, China \\ ${ }^{3}$ College of Information and Electronics, Beijing Institute of Technology, Kunming 100081, China
}

Correspondence should be addressed to Yanhui Guo; guoyanhui0818@kust.edu.cn

Received 8 January 2021; Revised 31 May 2021; Accepted 25 June 2021; Published 8 July 2021

Academic Editor: Chong Xu

Copyright (c) 2021 Yanhui Guo et al. This is an open access article distributed under the Creative Commons Attribution License, which permits unrestricted use, distribution, and reproduction in any medium, provided the original work is properly cited.

\begin{abstract}
The monitoring and early warning of a landslide in the reservoir area of a hydropower station are of great significance in the dam structure of the hydropower station and in the safety of people's life and property on the reservoir bank. In this study, a new ground-based interferometric synthetic aperture radar system LKR-05-KU-S100 was used to carry out field monitoring tests on Lagu landslide and Xiaozhaju landslide of Dahuaqiao hydropower station and No. 1 landslide on the left bank of Xiaowan hydropower station on the Lancang river. The results show that, during the monitoring period, Lagu landslide of Dahuaqiao hydropower station and No. 1 landslide on the left bank of Xiaowan hydropower station are basically stable, and the deformation trend of Xiaozhaju landslide is obvious so it should undergo continuous monitoring. At the same time, the field monitoring test also shows that the new ground-based interferometric synthetic aperture radar system LKR-05-KU-S100 has the advantages of high precision and long-distance, all-day, all-weather, and large-scale monitoring and has unique advantages and broad application prospects for the overall deformation monitoring of large landslides in the reservoir area.
\end{abstract}

\section{Introduction}

Landslide is a sliding geological phenomenon of rock and soil slope along the shear failure surface $[1,2]$. Landslide is a natural disaster that causes great economic losses after earthquake in the world $[3,4]$. In the reservoir area of a hydropower station, the rise and fall of the water level caused by water storage and flood discharge directly affects the stability of the upstream and downstream bank of the reservoir area and will cause hidden dangers to the safety of cruise ships, dams, and power generation facilities in the reservoir area. Monitoring the key landslides in a certain range of upstream and downstream of a hydropower station has great engineering significance. In recent years, many detections and monitoring techniques have been applied to landslide research $[5,6]$, including landslide regional investigation, landslide displacement monitoring, landslide disaster assessment, and landslide risk assessment [7], among which landslide monitoring is the most basic and important work $[8,9]$.

Compared with GPS, total station, digital level, optical remote sensing, three-dimensional laser scanning, and other monitoring technologies $[10,11]$, ground-based synthetic aperture radar interferometry (GB-InSAR) technology, which has been widely used, has the advantages of wide coverage, high resolution, no need for ground control points, and having archived data [10-12]. Compared with spaceborne and airborne platform SAR, GB-InSAR has more advantages in revisit cycle, ease of use, monitoring perspective, and use cost [13-15]. By the application of ground-based synthetic aperture radar in engineering disaster monitoring research, Liu et al. monitored and 
evaluated the postdisaster stability of Dashuchang landslide and analyzed the postdisaster deformation evolution characteristics of the landslide, and the system used was the GBinsar system IBIS-L developed by Italian Ingegneria Dei Sistemi company and University of Florence [16]. Qiu et al. and Xing et al., respectively, used the ground-based synthetic aperture radar ibis-l system to observe the open field deformation of Geheyan dam and, through data analysis, analyzed the overall monitoring results and deformation of the dam $[17,18]$. Zhang et al. monitored and analyzed the deformation of Lushui dam in Chibi City before and after water discharge through fast-GBSAR equipment with FMCW technology developed by Metasensing company, Netherlands [19]. Li et al. organically connected the deformation data obtained from GB-InSAR of open pit slope of East No. 2 coal mine with GIS through the integration of GBInSAR and GIS, which verified that this method can be well used in the emergency monitoring and early warning of a landslide disaster [20]. The MPDMR-05-LSA1701 GBInSAR system developed by the direction map Technology Co., Ltd., of Mongolia Autonomous Region in China was used to carry out deformation monitoring on the red stone rock slope of Niulanjiang barrier lake in Yunnan Province, and the stability of the rock slope was analyzed [21, 22]. Luo et al. used the ArcFMCW-SAR system developed by Institute of electronics, Chinese Academy of Sciences, to extract digital elevation model of a landslide and monitor the landslide [23].

To sum up, there are some GB-InSAR devices in China, which also play a role in many applications. However, the research of the GB-InSAR system in China is still insufficient, and more research is still needed. Simultaneously, there are only few reports about the application of GBInSAR made in China in the deformation monitoring of superlarge landslides in the reservoir area of the hydropower station. In this paper, a new domestic ground-based interferometric synthetic aperture radar (the model is LKR-05KU-S100) monitoring system is applied to study the Lagu landslide and Xiaozhaju landslide of Dahuaqiao hydropower station in Lancang River Basin and the No. 1 landslide on the left bank of Xiaowan hydropower station. Through online monitoring tests, the accuracy and applicability of the system are analyzed. The research results are helpful for monitoring and warning of large-scale landslide disasters and radar monitoring. The application of the system is of great significance.

\section{Measurement Principle of Ground-Based Synthetic Aperture Radar Technology}

2.1. Basic Working Principle of GB-InSAR. The basic principle of GB-InSAR is to form a linear synthetic aperture by moving the radar antenna in the ground-based orbit and obtain a high-resolution two-dimensional image of the observation area through the stepped frequency continuous wave technology [24]. By combining the SAR complex images acquired at different times in the same target area and comparing the target phase difference at different times, the target's millimetre precision displacement information can be obtained $[25,26]$. Then, the network remote control system is used to realize all-weather automatic monitoring. When the deformation amount and deformation rate of the slope reach the early warning level, the disaster information is sent in advance. In the coordinate axis of the two-dimensional image acquired by the radar, the orbit's direction is azimuth, and the direction along the radar wave is a range (see Figure 1).

In Figure 1, the moving trajectory of SAR is from $C_{1}$ to $C_{n}$, that is, the transmitting position of the coherent pulse signal is $C_{1}, C_{2}, \ldots, C_{n}, L$ is the orbit length, $r$ is the distance between the radar and the target, and $A$ is the scanning target point. The azimuth resolution is $\delta_{\theta}=\lambda / 2 L$, where $\lambda$ is the electromagnetic wavelength transmitted by the radar; the range resolution is $\delta r=c / 2 B$, where $c$ is the propagation velocity of an electromagnetic wave in vacuum and $B$ is the bandwidth of the radar transmitted signal (see Figure 2).

2.2. Differential Interferometry. Differential interference refers to data acquisition by the radar system for the same target at different time points to obtain the phase difference of the same phase element at different times, to calculate the corresponding displacement. The schematic diagram is shown in Figure 3.

Assuming that the target has a certain displacement at time $t_{1}$ and $t_{2}$ and the radar is in the same position to observe the target area at two times, it can be obtained that the distance between the radar and the target under two time conditions are $\rho\left(t_{1}\right)$ and $\rho\left(t_{2}\right)$, respectively. The relative displacement $\Delta \rho$ of the target can be obtained by interference processing. The linear relationship between the phase difference $\nabla \varphi$ and deformation of the line of sight $\Delta \rho$ can be expressed as follows [27]:

$$
\nabla \phi=\frac{4 \pi}{\lambda}\left[\rho\left(t_{1}\right)-\rho\left(t_{2}\right)\right]=\frac{4 \pi}{\lambda} \Delta \rho .
$$

After obtaining the SAR complex images acquired at different times, the target's displacement information is obtained by comparing the target's phase difference at different times. If the ground-based SAR acquires two SAR complex images $I_{1}$ and $I_{2}$ of the same target area at different times, assuming that the images are completely matched, the corresponding phase difference can be obtained by conjugate multiplication of the corresponding pixels of the complex image, forming the interferogram. Thus, the phase difference $\varphi(p)$ of any pixel $P$ in the interferogram can be obtained as follows:

$$
\nabla \varphi(p)=\angle\left(I_{2}(p) \cdot I_{1}^{*}(p)\right)=\varphi_{2}(p)-\varphi_{1}(p),
$$

where “*” denotes complex conjugation and $\angle I_{n}(p)=\varphi_{n}(p), n=1$ or 2 .

From the phase difference after unwrapping, the deformation of the target in the image along the radar line of sight can be calculated as follows:

$$
\nabla R(p)=\frac{c}{4 \pi f_{c}} \cdot \nabla \varphi(p)
$$




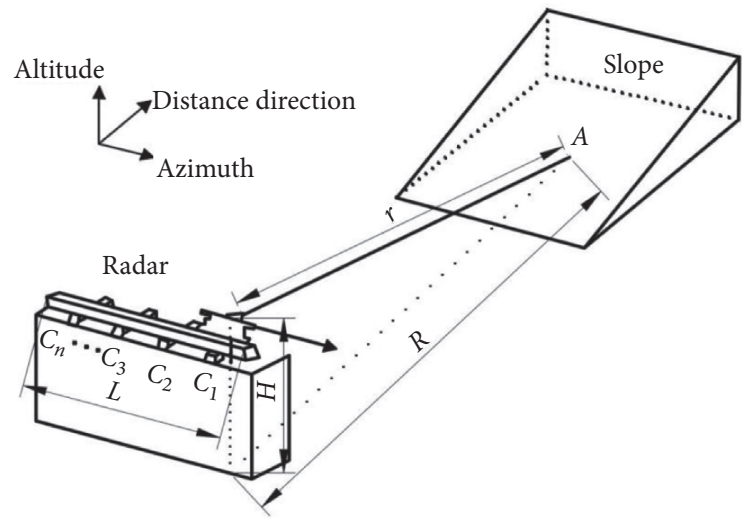

FIGURE 1: Radar imaging azimuth diagram.

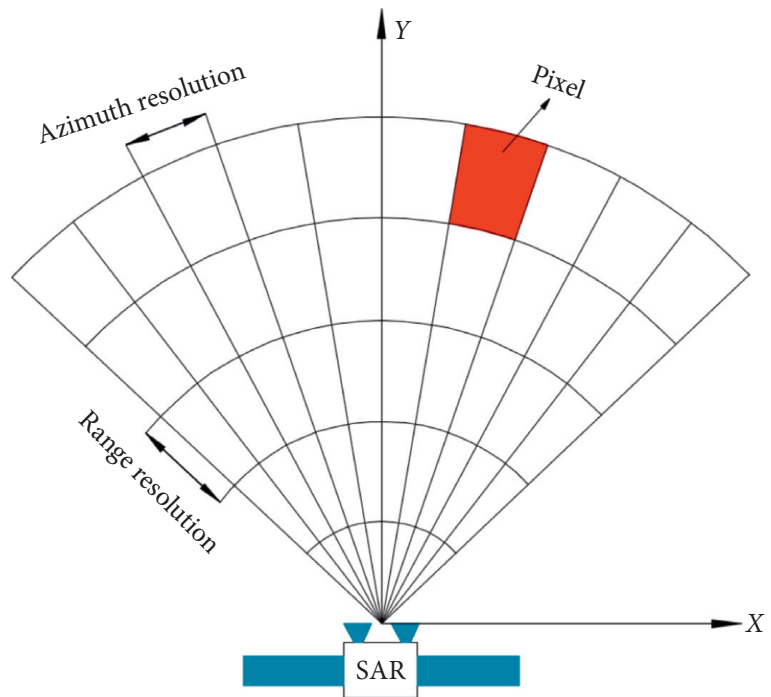

Figure 2: GB-InSAR resolution diagram.

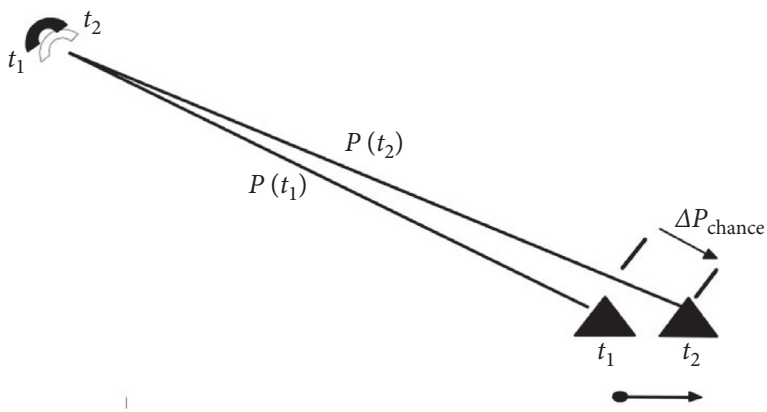

FIGURE 3: Schematic diagram of differential interferometry.

where $f_{c}$ is the center frequency of the transmitted signal, $\nabla R(p)$ is the phase difference, and $c$ is the propagation velocity of the electromagnetic wave in vacuum.

To sum up, the ground-based SAR differential interferometry combines the SAR complex images acquired at different times in the same target area. It obtains the target's displacement and deformation information by comparing the target's phase difference at different times.

\section{Composition and Main Parameters of the New Ground-Based Synthetic Aperture Radar System LKR-05-KU-S100}

3.1. Composition of New LKR-05-KU-S100 System. This paper adopts the advanced LKR-05-KU-S100 system developed by China Beijing Polytechnic Leike Electronic Information Technology Co., Ltd., as shown in Figure 3. The system consists of a radar host, data processing unit, linear slide, and energy supply unit. The high-precision electronic control displacement table used in the system can ensure the monitoring operation's stability and reliability. The system frequency modulated continuous wave radar can transmit the linear frequency modulated electromagnetic wave signal. The imaging time is greatly shortened, and the observation time is less than 2 minutes. The system's real-time monitoring data processing software has two-dimensional and three-dimensional modes, in which terrain-related information from the monitoring imaging results can be easily identified. The system's data processing unit can build a database and publish the radar monitoring data in real time through the website. Also, radar monitoring data can be transmitted in real time by remote wireless mode.

3.2. Main Functions and Parameters of the System. The main functions of the LKR-05-KU-S100 radar system are as follows. (a) It can carry out long-distance, large-scale, and noncontact monitoring of the monitoring target area. Simultaneously, it can monitor the target object's vibration information, and it has the function of remote control observation. (b) It can work for a long time, and the continuous working time is more than $100 \mathrm{~d}$. (c) The radar system has high precision, which can reach the submillimetre level. (d) It functions using energy-saving equipment and environmental protection, data acquisition, and short processing time. The frequency band of the radar signal is $\mathrm{Ku}$, the signal type is SFCW, the aperture type is synthetic aperture, the gain mode is $18 \mathrm{dbi}$, the polarization mode is $\mathrm{VV}$, and the main lobe- $3 \mathrm{db}$ angle width is $75^{\circ} \mathrm{H} /$ $90^{\circ} \mathrm{V}$. The parameters of the LKR-05-KU-S100 system are shown in Table 1. The image processing interface of radar monitoring information is shown in Figure 4.

\section{Application of New GB-InSAR in Deformation Monitoring of Lagu Landslide in Dahuaqiao Hydropower Station}

4.1. Geological Survey of Lagu Landslide. Dahuaqiao hydropower station is located in the Township, Lanping County, Nujiang Prefecture, Yunnan Province [28]. It is the sixth cascade hydropower station among the eight cascade hydropower stations planned in the Lancang river mainstream hydropower base's upstream reach. The hydropower station dam is a concrete gravity dam, with a crest length of $231.5 \mathrm{~m}$, a dam height of $106 \mathrm{~m}$, a total reservoir capacity of 293 million $\mathrm{m}^{3}$, and an installed capacity of $920000 \mathrm{~kW}$. The location of Dahuaqiao hydropower station is shown in Figure 5. 
TABLE 1: Basic parameters of the LKR-05-KU-S100 system.

\section{Resolution}

Monitoring distance

Monitoring accuracy

Work environment

Software

Customizability
Range resolution: $0.3 \mathrm{~m}$

Azimuth: $4 \mathrm{mrad}$ (customizable)

$10 \mathrm{~m} \sim 4000 \mathrm{~m}$
$0.1 \mathrm{~mm}$
$-25^{\circ} \mathrm{C} \sim 60^{\circ} \mathrm{C}$

The software has open data interface, simple interface, and convenient operation Multisource data fusion can be realized

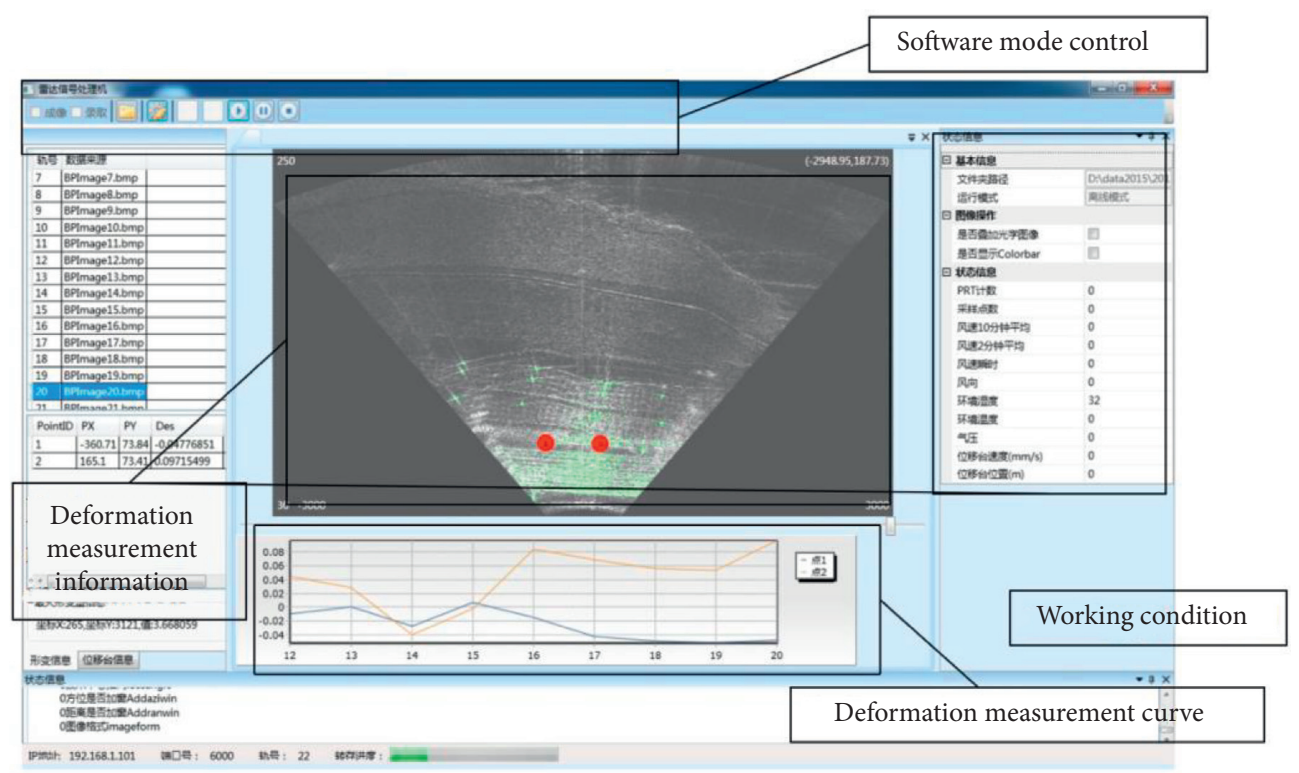

FIGURE 4: Radar monitoring information imaging processing interface.

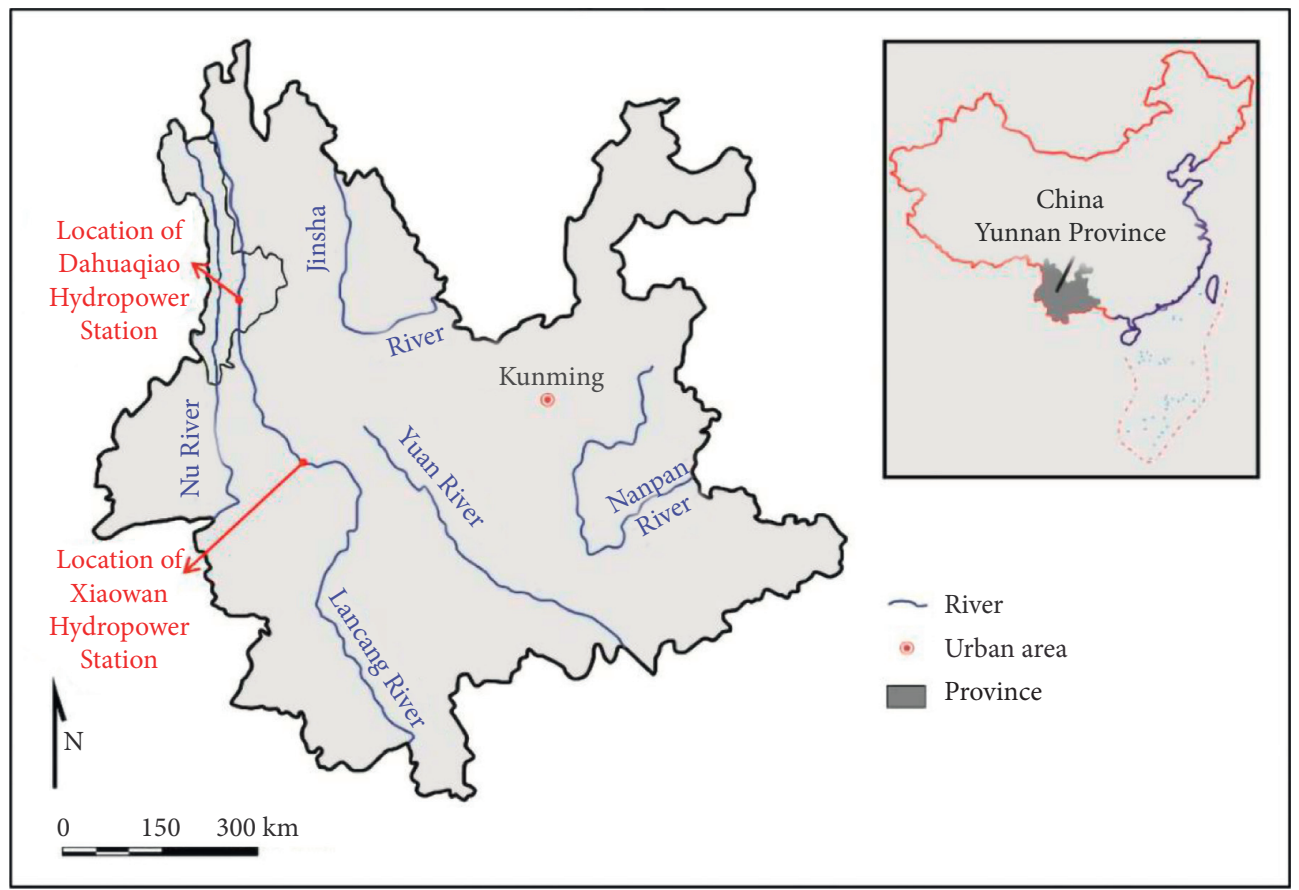

FIGURE 5: Location distribution of hydropower stations. 
Lagu landslide is about $12.5 \mathrm{~km}$ away from the lower dam site, and its elevation distribution is between $1430 \mathrm{~m}$ and $2000 \mathrm{~m}$. The whole slope is fan-shaped, wide in front, and narrow in back, spreading in the NS direction, and the front edge is about $1.6 \mathrm{~km}$ along the river. In the whole slope area, the potential is high in the west and low in the east, high in the south and low in the north, and, in some parts, it is a stepped slope landform, steep in the upper part and gentle in the lower part. The front edge of the landslide reached the edge of the Lancang River (the water level of the Lancang River is $1425-1427 \mathrm{~m}$ in the dry season), forming a nearly NS trending bank slope with a slope of $40^{\circ}$ to $50^{\circ}$, and some bank slopes were unstable and sliding. There are five large deep gullies in the slope, one in the upstream and one downstream. On the whole, Lagu landslide is in three free sides; only the rear edge is connected with the mountain. There are few original natural vegetation on the whole landslide's surface, and most of them are seasonal crops. Laguzhong village, Qingkouzhai, and other settlements are distributed in the middle of the slope's upper reaches. The location of Lagu landslide is shown in Figure 6.

The landslide mass is mainly composed of quaternary colluvial debris with soil. Some sections include the purplered slate with toppling deformation and extreme weathering at the lower part. The rock strata are seriously toppled and cracked, and the rock core is mostly fragmentary, and some rock strata are wrinkled. The content of rock fragments in the soil is high, showing subangular shape. The lithology is purplish-red slate and grey-green slate. The diameter of rock fragments is generally $2-15 \mathrm{~cm}$, the thickness is $15-30 \mathrm{~m}$, and the local thickness is $52 \mathrm{~m}$. According to the drilling exposure, there is no unified bottom sliding surface in the landslide, but the second sliding surface is developed locally. The sliding zone is mainly composed of grey-green gravel, debris, and argillaceous material, with a gravel particle size of $3-8 \mathrm{~mm}$ and subangular shape, accounting for about $30 \%$. The rock score is in the short column to column shape, with compact structure and high density, showing consolidated or semiconsolidated shape. The optical image of Lagu landslide is shown in Figure 7.

4.2. Monitoring and Analysis of Lagu Landslide. To monitor the deformation of Lagu landslide, according to the actual situation of the site and the working principle of the equipment, the measuring point of Lagu landslide is set on the opposite bank of the landslide, and the measuring point is about $390 \mathrm{~m}$ away from the landslide. Figure 8 shows the radar intensity image of Lagu landslide, and Figure 9 shows displacement variation with time of characteristic points of Lagu landslide.

According to the comparative analysis of the radar image and the optical photo of the slope, the following conclusions can be made. (a) The observation distance is longer than that of the conventional total station. (b) In the radar intensity influence map, the echo characteristics of the highway are stronger and more obvious. (c) The intensity characteristics of the surface exposed and gully areas in the radar image are more obvious. (d) The radar echo is relatively weak at the surface trees and clutter in the monitoring area, and the characteristics are not obvious in the places with dense vegetation such as grass. To sum up, when monitoring the slope, although the measuring point is far away from the slope and affected by the surface vegetation, the radar echo in some areas is weak. The characteristics are not very obvious, but the structures such as highway pavement and cutting in the landslide area and the areas with exposed slope surface have a strong echo, and the characteristics are undeniable, so the overall stability of Lagu landslide can be evaluated according to these typical areas' effective real-time monitoring. (e) There are obvious bright lines at the zero point of azimuth, which are different from the actual observation scene to a certain extent, and the possible reason is that azimuth signal compression is not done well in the process of data processing. In the analysis, careful screening should be carried out to reduce the impact of this area. Simultaneously, it is necessary to further improve and optimize the monitoring system and enhance the compression effect of the azimuth signal in the process of data processing so that the monitoring results at the azimuth zero point should be consistent with the actual deformation as far as possible.

The cumulative deformation distribution map of Lagu landslide is shown in Figure 10. The analysis shows the following. (a) Limited to the monitoring time, the maximum displacement of the slope mainly occurs in the place with dense vegetation, which indicates that the dense vegetation has a certain impact on the monitoring accuracy. (b) During the monitoring period, the displacement of the main buildings in the monitoring area is minimal, which indicates that the Lagu landslide is basically in a stable state during the monitoring period. (c) Considering that the front of Cangjiangqiao landslide was submerged in the later stage of Dahuaqiao hydropower station reservoir impoundment, which may induce the revival of an ancient landslide, the long-term monitoring of the slope by GB-InSAR is necessary and feasible.

\section{Application of New GB-InSAR in Deformation Monitoring of Xiaozhaju Landslide}

5.1. Geological Survey of Xiaozhaju Landslide. Xiaozhaju landslide deposit is located on the left bank of the Lancang River in the upstream of the dam site, about $7 \mathrm{~km}$ away from the dam site (see Figure 6). The elevation of the front edge of the accumulation body is $1420 \mathrm{~m}$ to the riverside. The back edge elevation is $1660 \mathrm{~m}$, the height difference is about $240 \mathrm{~m}$, and the width along the river is about $800 \mathrm{~m}$, and the longitudinal length is about $500 \mathrm{~m}$. The slope is about $30^{\circ}$ below the elevation of $1530 \mathrm{~m}$, about $20^{\circ}$ above the elevation of $1530 \mathrm{~m}$, and $40^{\circ}$ to $50^{\circ}$ locally. Zhaju village is located at the back edge of the accumulation body, and the volume of the accumulation body is estimated to be about $800 \times 10^{4} \mathrm{~m}^{3}$ [28].

Xiaozhaju is mainly located above the left bank of the Dahua bridge, with an average width of $300 \mathrm{~m}$, an average 


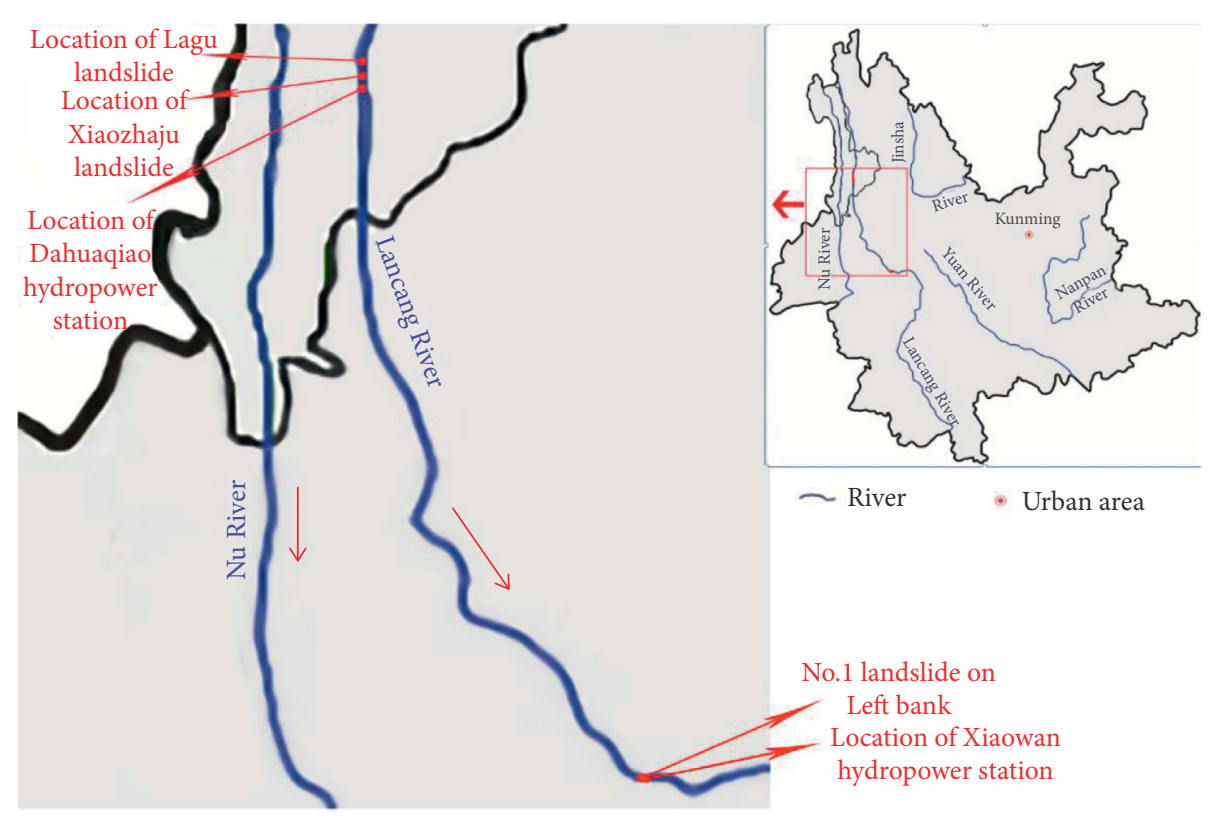

FIgURE 6: Schematic diagram of landslide location.

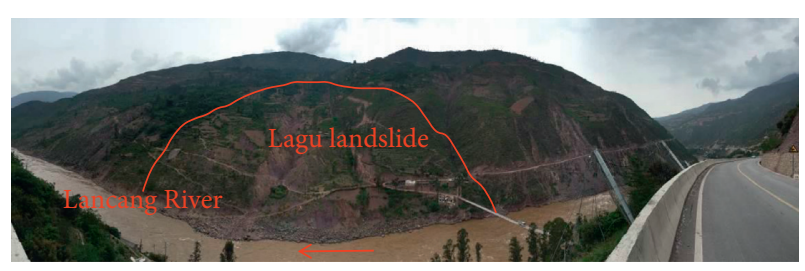

Figure 7: Optical photo of Lagu landslide.

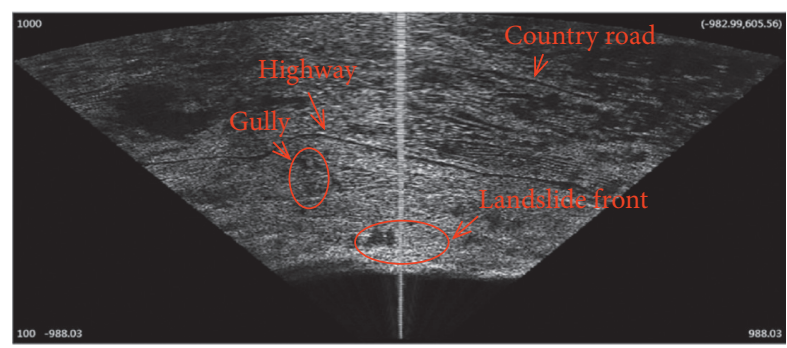

FIgURE 8: Radar intensity image of Lagu landslide.

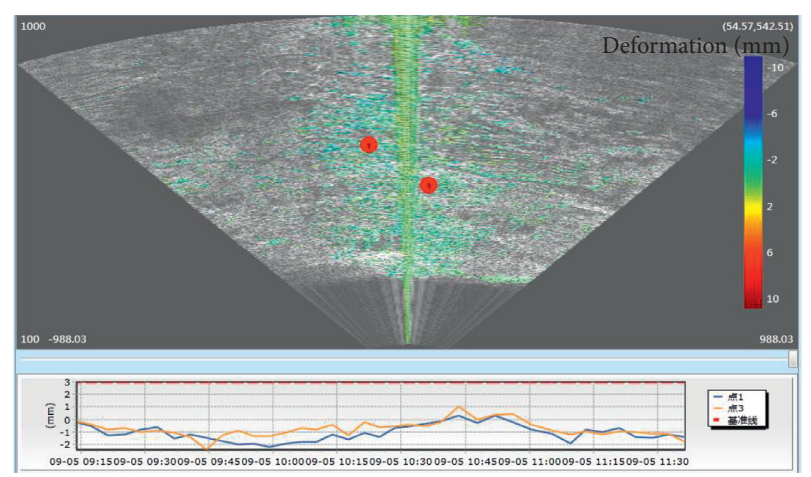

FIGURE 9: Displacement variation with time of characteristic points of Lagu landslide. area of $8.3 \times 10^{4} \mathrm{~m}^{2}$, an average perimeter of $1300 \mathrm{~m}$, an average thickness of $12 \mathrm{~m}$, a maximum thickness of $18 \mathrm{~m}$, and a volume of $38.4 \times 10^{4} \mathrm{~m}^{3}$. From the aspect of landform, the back edge is in the shape of "armchair," and there are longitudinal cracks in the middle and lower part of the back edge wall, with the width of about $20 \mathrm{~cm}$. The gradient of the Dahua bridge axis is about $40^{\circ}$ below $1450 \mathrm{~m}$, about $25^{\circ}$ to $30^{\circ}$ above $1450 \mathrm{~m}$, and about $20^{\circ}$ above $1530 \mathrm{~m}$. There is a spoil ground under the highway upstream of the bridge axis, which mainly stores the spoil from the river's original highway tunnel. There are cracks at the top of the spoil and the edge of the upstream side. The terrain on the downstream side of the bridge axis is concave to the mountain, with an elevation of about $1450 \mathrm{~m}$ and a shear-out surface with a thickness of about $10-20 \mathrm{~cm}$. The terrain at the lower part is steep. The optical image of Xiaozhaju landslide is shown in Figure 11.

5.2. Monitoring and Analysis of Xiaozhaju Landslide. The measuring point of Xiaozhaju landslide is located at the highway's side on the opposite bank of the landslide, and the horizontal distance from the landslide is about $280 \mathrm{~m}$. The radar intensity image of Xiaozhaju landslide is shown in Figure 12. It can be found as follows. (a) In the radar image, the echo characteristics of buildings and slopes such as houses, roads, cutting, and embankment are relatively strong, and the radar image characteristics are relatively obvious. (b) In the radar image, the echo characteristics of the slope and steps of the spoil ground are relatively strong, and the characteristics are also relatively obvious. (c) The radar echo characteristics of the exposed surface in the landslide area are relatively strong, and the characteristics are relatively obvious. (d) The echo characteristics of the landslide monitoring area are relatively strong, the radar echo is relatively weak, and the characteristics are not very 


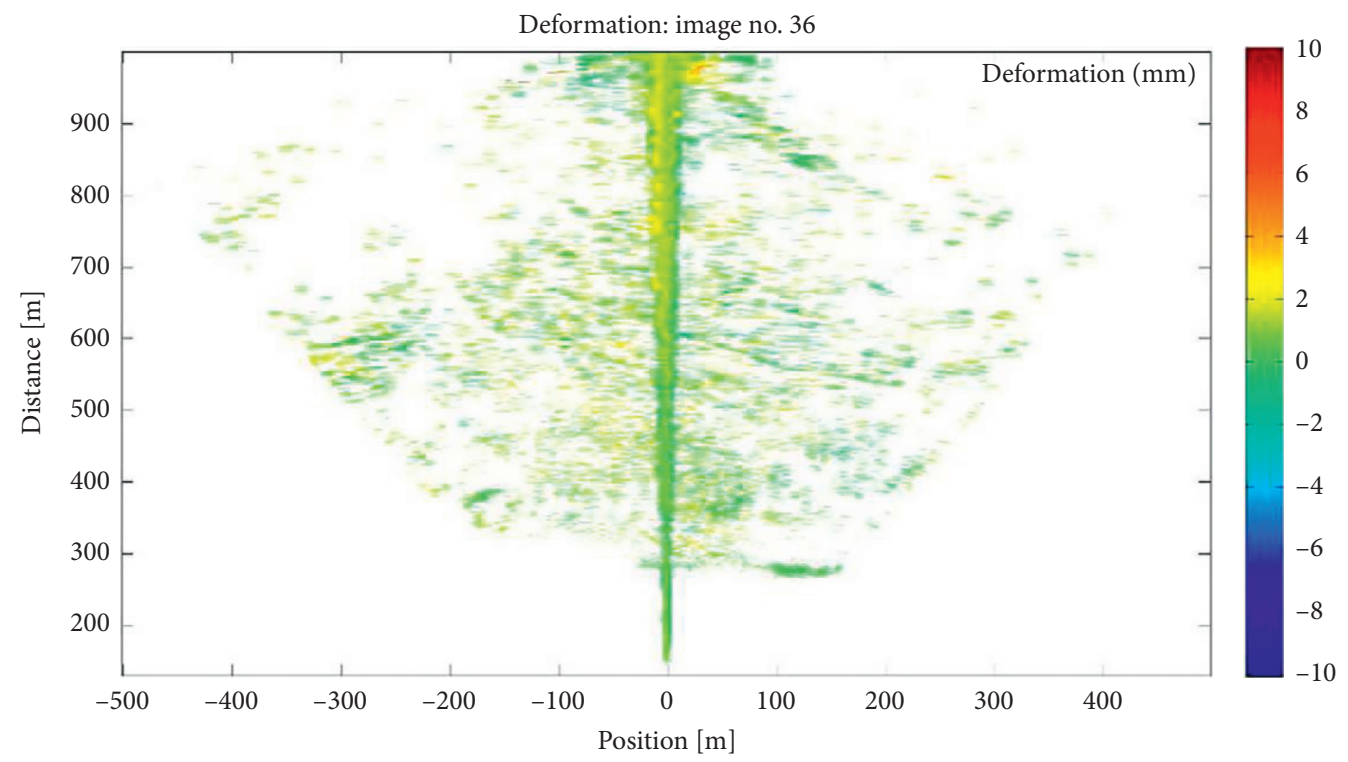

Figure 10: Cumulative deformation distribution of Lagu landslide.

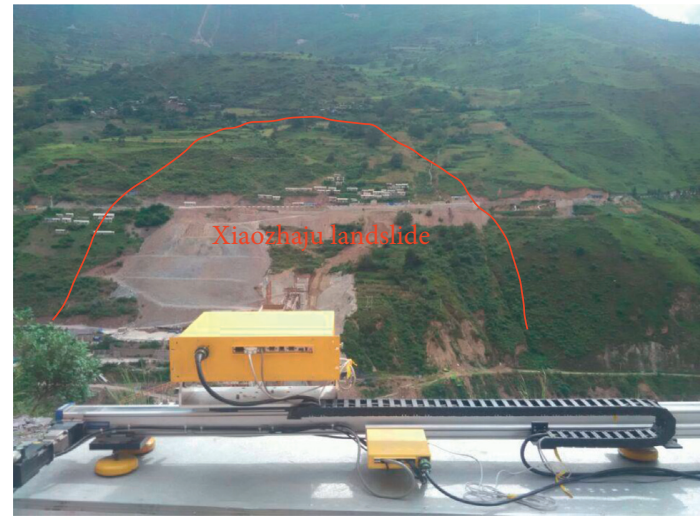

FIgURE 11: Optical photo of Xiaozhaju landslide.

obvious in the areas with dense vegetation such as trees and weeds. To sum up, in the monitoring of Xiaozhaju landslides, the radar image of Xiaozhaju landslide is clearer than that of Lagu landslide because the monitoring distance is lower than that of Lagu landslide, which indicates that the clarity of the radar image is improved with the decrease of distance. In the landslide area, the echo characteristics of the spoil ground, houses, and roads are relatively strong, and the characteristics are undeniable. According to these typical areas, the overall stability of Xiaozhaju landslide can be effectively monitored in real time.

Figure 13 shows displacement variation with time of characteristic points of Xiaozhaju landslide, and Figure 14 shows the cumulative deformation curve of Xiaozhaju landslide. Because during the monitoring period, it is raining, and Xiaozhaju landslide is in the deformation acceleration period. Due to some special reasons, the monitoring time is short, and it can be found in the figure that, during the monitoring period, the maximum displacement of No. 4 and No. 5 measuring points is about $2 \mathrm{~mm}$, the maximum displacement of No. 1 measuring point is $4 \mathrm{~mm}$,

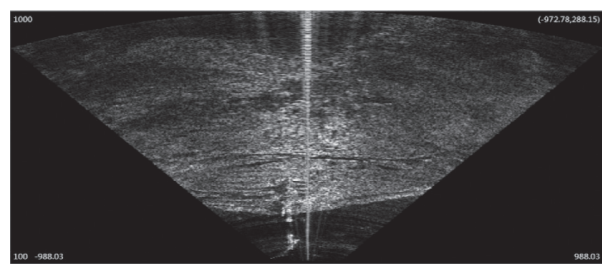

FIgURE 12: Radar intensity image of Xiaozhaju landslide.

and the maximum displacement of No. 2 measuring point is $6 \mathrm{~mm}$. Therefore, the deformation and displacement of the landslide tend to increase. Combined with the engineering geological conditions and the observation of ground fissures, it is considered that the deformation of Xiaozhaju landslide is obvious during the monitoring period, and the online monitoring and early warning and prediction work should be continuously strengthened.

\section{Application of New GB-InSAR in Deformation Monitoring of No. 1 Landslide on the Left Bank of Xiaowan Hydropower Station}

6.1. Geological Survey of No. 1 Landslide on the Left Bank of Xiaowan Hydropower Station. Xiaowan hydropower station is located in the middle reaches of the Lancang River at the junction of Nanjian County of Dali Prefecture and Fengqing County of Lincang City, Yunnan Province, $455 \mathrm{~km}$ away from Kunming (see Figure 5). Xiaowan hydropower station is the second level of "two reservoirs and eight levels" in the hydropower planning of the middle and lower reaches of the Lancang River [29]. The upstream is Gongguoqiao hydropower station, and the downstream is Manwan hydropower station. Xiaowan reservoir is the "leading reservoir" of cascade hydropower stations, with a total storage capacity of about 15 billion $\mathrm{m}^{3}$ and a regulation capacity of nearly 10 billion $\mathrm{m}^{3}$, which has a regulation capacity for many years. 


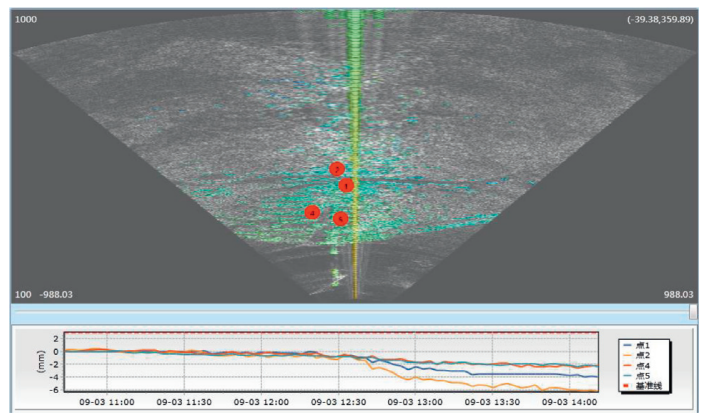

Figure 13: Displacement variation with time of characteristic points of Xiaozhaju landslide.

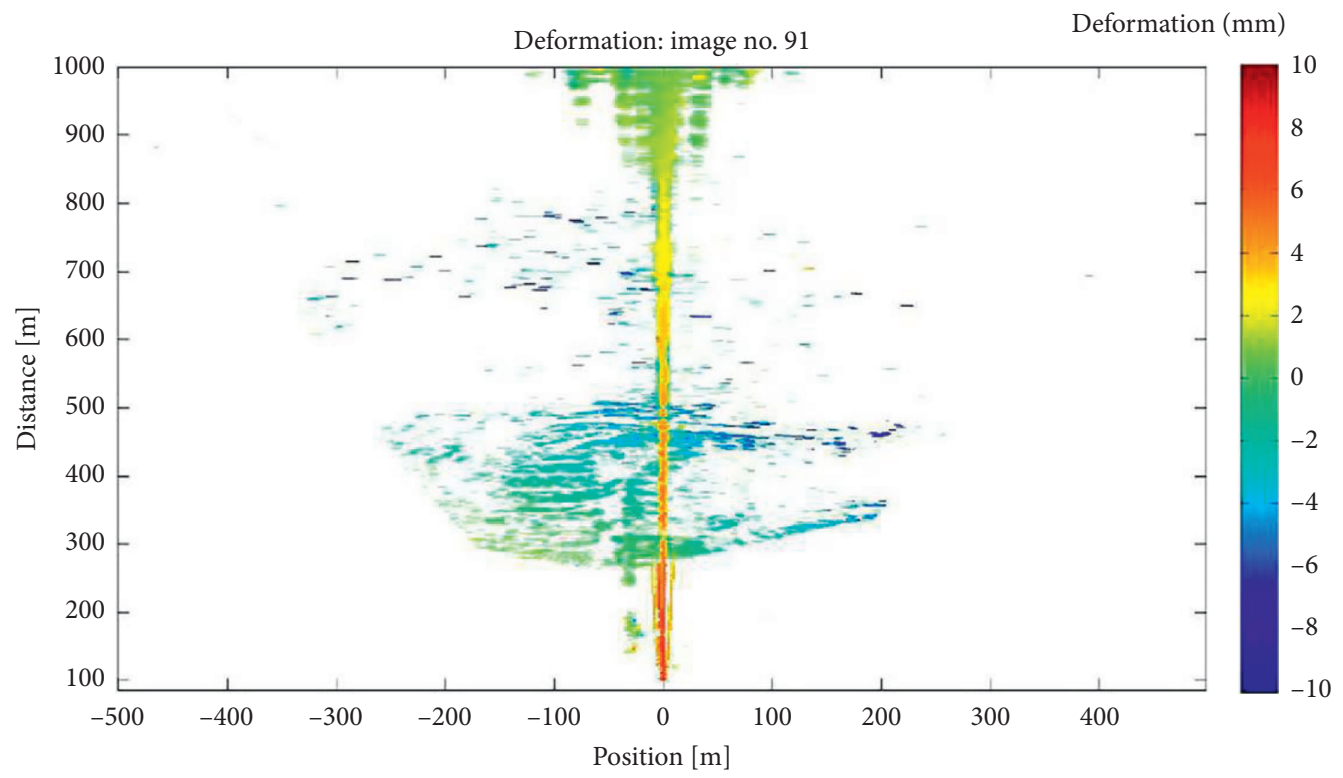

FIgURE 14: Cumulative deformation distribution of Xiaozhaju landslide.

Xiaowan hydropower station is a "leading reservoir" in the middle and lower Lancang River reaches, mainly for power generation, and has comprehensive utilization benefits such as flood control, irrigation, sediment retention, and shipping. The dam is a concrete double curvature arch dam with a height of $292 \mathrm{~m}$, a crest elevation of $1245 \mathrm{~m}$, a crest length of $922.74 \mathrm{~m}$, a top width of $13 \mathrm{~m}$, and a bottom width of $69.49 \mathrm{~m}$. After the dam's completion, a reservoir of 15.132 billion $\mathrm{m}^{3}$ will be formed, and the installed capacity of the hydropower station will be 4.2 million $\mathrm{kW}$. The normal water level of the reservoir is $1240 \mathrm{~m}$. Figure 15 shows the optical image of No. 1 landslide on the left bank of Xiaowan hydropower station.

\subsection{Monitoring and Analysis of No. 1 Landslide on the Left} Bank. The radar intensity influence diagram of No. 1 landslide on Xiaowan hydropower station's left bank is shown in Figure 16. It can be seen from the diagram that the No. 1 landslide measuring point on the left bank is located on the side of the highway on the opposite bank of the landslide, and the horizontal distance from the landslide is about $1090 \mathrm{~m}$. It can be found as follows. (a) In the radar image, the echo characteristics of roads, cutting, and embankment

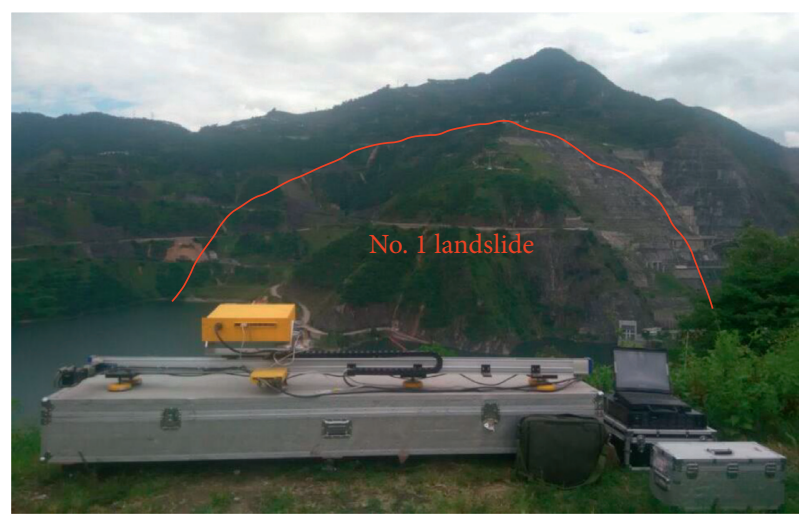

FIgURE 15: Optical image of No. 1 landslide on the left bank of Xiaowan hydropower station.

slopes are relatively strong, and the radar image characteristics are relatively obvious. (b) The echo characteristics of the left abutment slope are relatively strong, and the characteristics are also relatively obvious. (c) The radar echo characteristics of the front edge of the landslide area are relatively strong, and the characteristics are relatively 


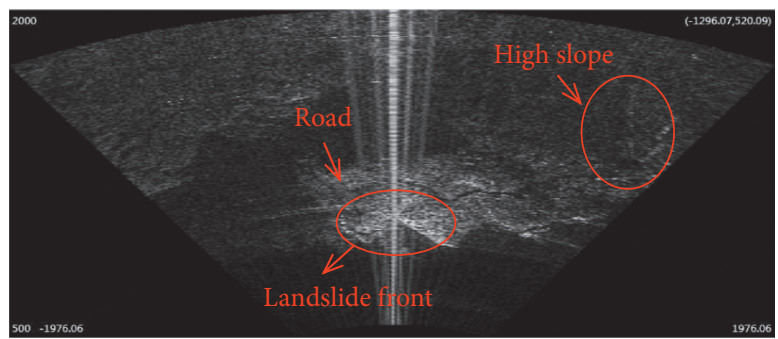

FIgURE 16: Radar intensity image of No. 1 landslide on the left bank.

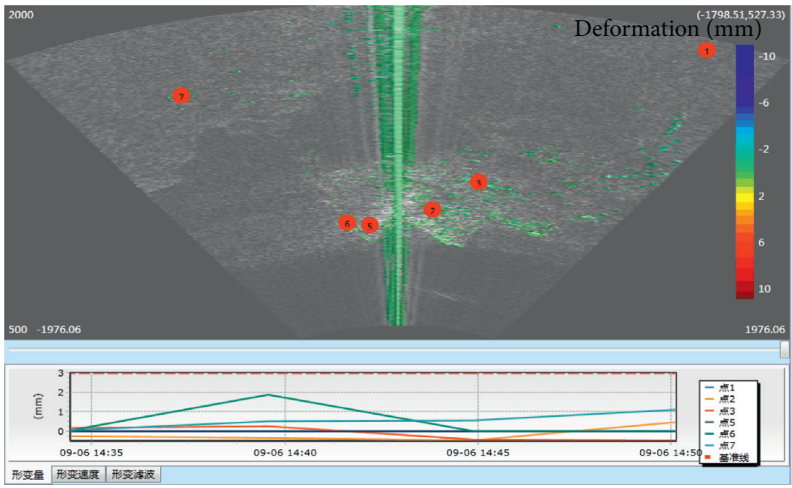

FIGURE 17: Displacement variation with time of characteristic points of No. 1 landslide on the left bank.

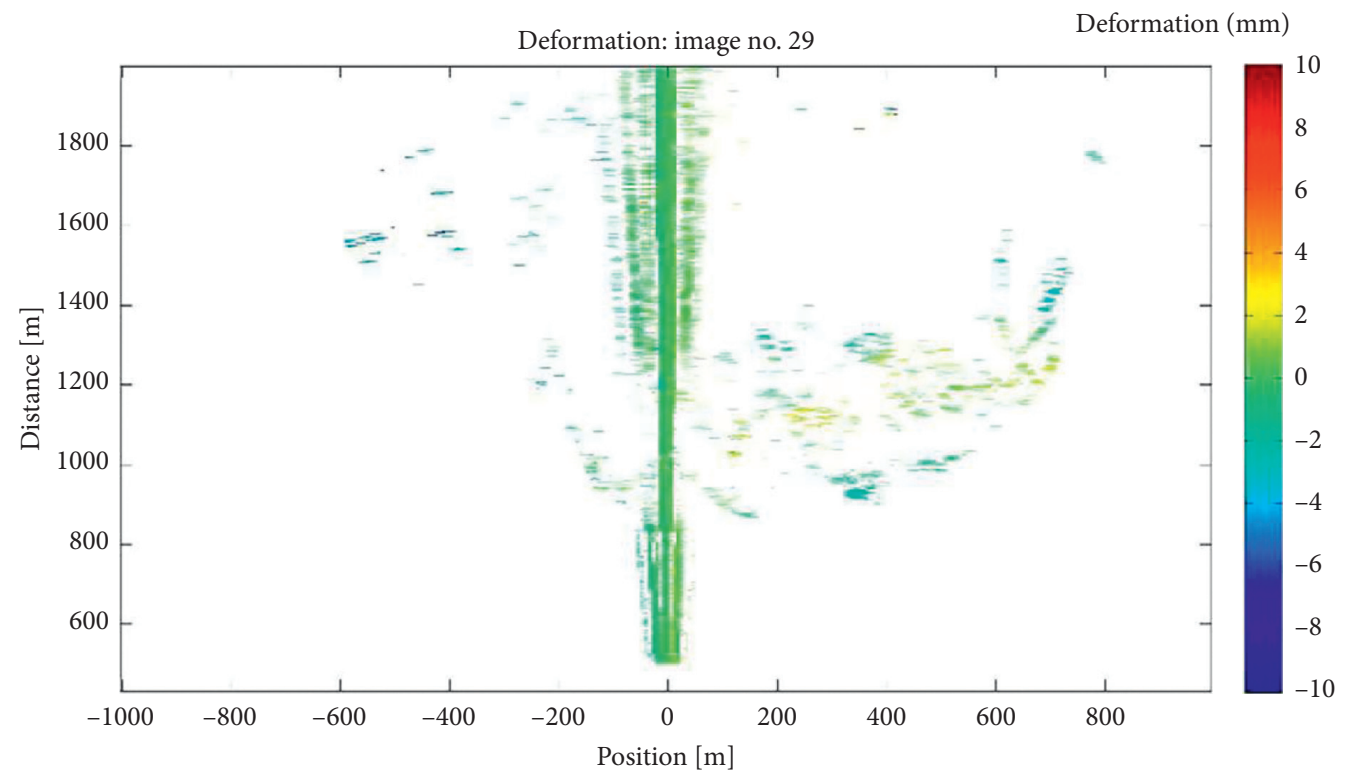

Figure 18: Cumulative deformation distribution of No. 1 landslide on the left bank.

obvious. (d) The radar echo ratio of the areas with dense vegetation such as trees and weeds on the surface of the landslide monitoring area is relatively high. (e) There are obvious bright lines at the zero point of azimuth, which are different from the actual observation scene, and should be carefully screened in the analysis.

Figure 17 shows displacement variation with time of characteristic points of No. 1 landslide on the left bank, and Figure 18 shows the cumulative deformation curve of the landslide. It can be found in the figure that, during the monitoring period, the slope displacement of Xiaozhaju landslide is small, and the maximum displacement of the selected 7 measuring points is about $2 \mathrm{~mm}$. Therefore, No. 1 landslide on the left bank is basically in a stable state. Considering that, in the later stage of Xiaowan hydropower station, the water level at the front edge of the landslide rises and repeatedly falls, which may lead to the revival of the landslide, and the landslide is close to the dam site, which has 
a great impact on the safety of the dam structure, and it is essential to use GB-InSAR for long-term monitoring of the landslide, especially in the process of water storage and flood discharge.

\section{Conclusions}

In this study, the Chinese new ground-based synthetic aperture radar system LKR-05-KU-S100 was used to conduct field monitoring tests on Lagu landslide and Xiaozhaju landslide of Dahuaqiao hydropower station in Yunnan Province, and No. 1 landslide on the left bank of Xiaowan hydropower station.

(1) Monitoring the surface vegetation in the landslide area greatly impacts the monitoring accuracy. When the vegetation is dense, the monitoring accuracy will decrease. Therefore, the data of the landslide surface vegetation area need to be carefully screened and handled.

(2) For the bare surface of houses, buildings, highways, and spoil ground in the landslide area, the echo characteristics are strong, the measurement accuracy is high, and the error is small. Therefore, in the largescale monitoring of landslide, the areas with strong echo characteristics can be selected as the typical feature points as the basis for the overall deformation and stability analysis of the landslide.

(3) This test shows that the new LKR-05-KU-S100 ground-based synthetic aperture radar system has the advantages of high precision, long-distance, allday and all-weather monitoring, large measurement range, etc., and has unique advantages and good application prospects for the monitoring of large and extralarge landslides and other geological disasters. Reducing the influence of azimuth zero points and improving the measurement accuracy under the influence of surface vegetation still need further research and development.

\section{Data Availability}

The data used to support the findings of this study are available from the corresponding author upon request.

\section{Conflicts of Interest}

The authors declare that they have no conflicts of interest.

\section{Acknowledgments}

This study was supported and funded by the China Chile International (regional) cooperation and exchange key projects of National Natural Science Foundation of China (no. 41861134008), General Projects of Yunnan Basic Research Program (no. 2018FB075), Science and Technology Projects of Yunnan Province (science and technology for the benefit of the people, no. 2015RA069), and Key R\&D Projects in Yunnan Province (no. 202003AC100002).

\section{References}

[1] C. Zhao, Z. Lu, Q. Zhang, and J. de la Fuente, "Large-area landslide detection and monitoring with ALOS/PALSAR imagery data over Northern California and Southern Oregon, USA," Remote Sensing of Environment, vol. 124, pp. 348-359, 2012.

[2] M. Parise, "Landslide mapping techniques and their use in the assessment of the landslide hazard," Physics and Chemistry of the Earth-Part C: Solar, Terrestrial \& Planetary Science, vol. 26, no. 9, pp. 697-703, 2001.

[3] D. Massonnet and K. L. Feigl, "Radar interferometry and its application to changes in the earth's surface," Reviews of Geophysics, vol. 36, no. 4, pp. 441-500, 1998.

[4] S. H. Yun, H. Zebker, P. Segall, A. Hooper, and M. Poland, "Interferogram formation in the presence of complex and large deformation," Geophysical Rescarch Letters, vol. 34, no. 12, pp. 237-254, 2007.

[5] D. T. Sandwell and E. J. Price, "Phase gradient approach to stacking interferograms," Journal of Geophysical Research: Solid Earth, vol. 103, no. B12, pp. 30183-30204, 1998.

[6] P. A. Rosen, S. Hensley, I. R. Joughin et al., "Synthetic aperture radar interferometry," Proceedings of the IEEE, vol. 88, no. 3 , pp. 333-382, 2000.

[7] J. Wasowski and F. Bovenga, "Investigating landslides and unstable slopes with satellite multi temporal interferometry: current issues and future perspectives," Engineering Geology, vol. 174, pp. 103-138, 2014.

[8] P. Berardino, M. Costantini, G. Franceschetti et al., "Use of differential SAR interferometry in monitoring and modeling large slope instability at Maratea (Basilicata, Italy)," Engineering Geology, vol. 68, no. 1, pp. 31-51, 2003.

[9] Z. G. Wang, Study on Geological Hazards and Preventive Measures of Water Conservancy and Hydropower Projects in Southwest China, China Water and Power Press, Beijing, China, 2013.

[10] Z. G. Wang, W. He, and K. Wang, "Geological hazard prevention and environment protection for water conservancy and hydropower engineering," Chinese Journal of Geological Hazard and Control, vol. 23, no. 2, pp. 70-74, 2012.

[11] X. H. Wu, H. T. Ma, and J. Zhang, "Development status and application of ground-based synthetic aperture radar," Geomatics and Information Science of Wuhan University, vol. 44, no. 7, pp. 1073-1081, 2019.

[12] W. Q. Zhang, L. Wang, and X. Y. Qu, "Deformation monitoring and result analysis of loess landslide based on georobot," Engineering of Surveying and Mapping, vol. 28, no. 3, pp. 66-69, 2019.

[13] H. H. Yu, Y. F. Xu, and H. B. Xie, "Application of slope deformation monitoring based on three-dimensional laser scanning technology," Zhong-zhou Coal, vol. 12, pp. 111-113, 2015.

[14] G. X. Liu, B. Zhang, R. Zhang et al., "Monitoring dynamics of Hailuogou glacier and the secondary landslide disaster based on combination of satellite SAR and ground-based SAR," Geomatics and Information Science of Wuhan University, vol. 44, no. 7, pp. 980-995, 2019.

[15] L. B. Jiang, K. Yang, and L. Che, "Monitoring of 3D deformation of target by ground-based synthetic aperture radar," Bulletin of Surveying and Mapping, vol. 3, pp. 35-38, 2020.

[16] B. Liu, D. Q. Ge, L. Zhang et al., "Application of monitoring stability after landslide based on ground-based InSAR," Journal of Geodesy and Geodynamics, vol. 36, no. 8, pp. 674-677, 2016. 
[17] Z. W. Qiu, J. P. Yue, and X. Q. Wang, "Application of groundbased radar system IBIS-L to dam deformation analysis," Journal of Yangtze River Scientific Research Institute, vol. 31, no. 10, pp. 104-107, 2014.

[18] C. Xing, X. Q. Han, X. Zhou, and P. Wang, "Application of GB-SAR to dam monitoring," Journal of Yangtze River Scientific Research Institute, vol. 31, no. 7, pp. 128-134, 2014.

[19] H. Y. Zhang, K. Q. Zhou, Y. T. Song, and L. L. Li, "A novel FMCW GB-SAR based dam deformation monitoring," Journal of Yangtze River Scientific Research Institute, vol. 34, no. 12, pp. 33-37, 2017.

[20] R. R. Li, Z. Yang, and B. Yu, "Slope deformation monitoring of open pit coal mine by GIS integrated GB-InSAR," Bulletin of Surveying and Mapping, vol. 5, pp. 26-30, 2017.

[21] D. C. Lin, H. T. Ma, and B. H. Song, "Application of slope radar in emergency rescue of landslide," Journal of Safety Science and Technology, vol. 12, no. S1, pp. 284-289, 2016.

[22] X. Y. Li, T. J. Lei, and W. J. Chen, "Deformation monitoring and application of dam slope based on ground-based radar interferometry," Anhui Agricultural Science, vol. 48, no. 9, pp. 221-225, 2020.

[23] Y. Luo, H. Song, R. Wang, Y. Deng, F. Zhao, and Z. Xu, "Arc FMCW SAR and applications in ground monitoring," IEEE Transactions on Geoscience and Remote Sensing, vol. 52, no. 9, pp. 5989-5998, 2014.

[24] Q. Jiang, J. H. Peng, H. L. Yang, Q. B. Wu, and X. Z. Fei, “GBInSAR railway slope monitoring of improved small baseline subset technology," Science Surveying and Mapping, vol. 42, no. 12, pp. 140-145, 2017.

[25] P. Guo, H. Y. Zhang, L. Chen, K. Q. Zhou, and C. L. Wang, “A novel FMCW GB-SAR based bridge deformation measurement campaign," Bulletin of Surveying and Mapping, vol. 6, pp. 94-97, 2017.

[26] C. S. Jiang, J. Wang, and Y. T. He, “Application of ground synthetic aperture radar in dam safety monitoring," Chinese Journal of Geological Hazard and Control, vol. 28, no. 2, pp. 146-149, 2017.

[27] H. L. Yang, J. H. Peng, and H. Y. Cui, "Slope of large-scale open-pit mine monitoring deformations by using groundbased interferometry," Progress in Geophysics, vol. 27, no. 4, pp. 1804-1811, 2012.

[28] K. H. Sun, Y. H. Zhang, and X. N. Yang, "Type analysis of bank slope and prediction of bank collapse for reservoir area of Dahuaqiao hydropower station," Resources Environment \& Engineering, vol. 30, no. 3, pp. 369-373, 2016.

[29] H. Bao, K. K. Zhang, C. G. Yan et al., "Excavation damaged zone division and time-dependency deformation prediction: a case study of excavated rock mass at Xiaowan Hydropower Station," Engineering Geology, vol. 272, 2020. 